\title{
What is early COPD and why is it important?
}

\author{
Joan B. Soriano (1) ${ }^{1,2}$, Francesca Polverino ${ }^{3,4}$ and Borja G. Cosio (ii) 2,5 \\ Number 3 in the series "Controversies in COPD: What Can be Done to Move the \\ Field Forward?" \\ Edited by D.D. Sin
}

\begin{abstract}
Affiliations: ${ }^{1}$ Instituto de Investigación, Hospital Universitario de la Princesa (IISP), Universidad Autónoma de Madrid, Madrid, Spain. ${ }^{2}$ CIBER-Centro de Investigación en Red de Enfermedades Respiratorias, Madrid, Spain. ${ }^{3}$ Asthma and Airway Disease Research Center, University of Arizona, Tucson, AZ, USA. ${ }^{4}$ Lovelace Respiratory Research Institute, Albuquerque, NM, USA. ${ }^{5}$ Dept of Respiratory Medicine, Hospital Universitari Son EspasesIdISBa, Palma, Spain.
\end{abstract}

Correspondence: Joan B. Soriano, Instituto de Investigación Hospital Universitario de la Princesa (IISP), Universidad Autónoma de Madrid, Diego de León 62, Madrid 28030, Spain. E-mail: jbsoriano2đagmail.com

@ERSpublications

It is envisaged that preventive efforts and treatment of COPD can modify its clinical course http://ow.ly/KlfX30m98cF

Cite this article as: Soriano JB, Polverino F, Cosio BG. What is early COPD and why is it important? Eur Respir J 2018; 52: 1801448 [https://doi.org/10.1183/13993003.01448-2018].

ABSTRACT There is increasing interest in the origins of chronic obstructive pulmonary disease (COPD), as it is envisaged that preventive efforts and treatment can modify its clinical course. The concept of early COPD is not new, but it has recently regained interest, given new population data, recent cellular and molecular advances and insights from clinical trials. To date, many knowledge gaps in the nature of early COPD still exist, mainly because COPD has always been considered a disease of the elderly, and little attention has been paid to the pathological changes occurring in the lungs of individuals at risk before they develop clinically evident COPD. Future studies should focus on identifying early pathological manifestations of COPD in order to prevent its progression in susceptible individuals. In this review, we aim to summarise what is known on early COPD, from the epidemiological, cellular and clinical perspectives.

Previous articles in this series: No. 1: Kim V, Aaron SD. What is a COPD exacerbation? Current definitions, pitfalls, challenges and opportunities for improvement. Eur Respir J 2018; 52: 1801261. No. 2: Washko GR, Parraga G. COPD biomarkers and phenotypes: opportunities for better outcomes with precision imaging. Eur Respir J 2018; 52: 1801570.

Received: July 312018 | Accepted after revision: Oct 032018

Copyright $\odot$ ERS 2018 


\section{Introduction}

Chronic obstructive pulmonary disease (COPD) is a heterogeneous, common, preventable and treatable disease that is characterised by persistent respiratory symptoms and airflow limitation that are due to airway and/or alveolar abnormalities, usually caused by significant exposure to noxious particles or gases. This concept implies that we expect to find the disease in patients of a certain age when the pathophysiological changes are well established, which limits our capability to modify its natural history. However, COPD pathogenesis may begin much earlier, even before birth, as passive smoke exposure in utero is associated with increased adult COPD risk, with independence of active and passive smoke exposure in childhood, adolescence or adulthood [1]. In addition, individuals sustaining childhood respiratory impairment are at increased risk of reduced adult lung function [2]. Therefore, a number of challenges must be overcome before defining what is early COPD [3]. Current definitions do not help. For instance, MARTinez et al. [1] define early COPD as ever-smokers ( $\geqslant 10$ pack-years), aged $<50$ years and with any of the following abnormalities. 1) Forced expiratory volume in $1 \mathrm{~s}$ (FEV1)/forced vital capacity (FVC) less than the lower limit of normal; 2) compatible abnormalities on computed tomography (CT) (airway abnormality and/or emphysema); or 3) FEV1 decline ( $\geqslant 60 \mathrm{~mL}$ per year). Regrettably, in historical cohorts and often in current patients, imaging and serial lung function measurements are often unavailable.

What is clear is that early disease does not mean mild disease (table 1). The severity of any disease relates to the extent of functional impairment of the target organ and, in the case of COPD, severity has traditionally been determined by the degree of airflow limitation, mainly FEV1 [4], or by composite measures that express respiratory impairment and prognosis, such as the BODE (body mass index, airflow obstruction, dyspnoea and exercise capacity) [5] and ADO (age, dyspnoea and obstruction) [6] indices, among others [7]. The definitions of "early" versus "late" disease take as a reference point the time when the disease is diagnosed or studied for the first time. Thus, the terms early and late do not necessarily mirror the real time course of the disease. So far, COPD severity is indicative of the loss of lung function, whereas early relates to a timescale, and both may/may not be coincident in the same individual. Part of the confusion is that, at present, it is not possible to differentiate mild COPD of recent onset from earlier-onset COPD that has not progressed to a more severe stage of disease [8]. Some evidence indicates that the majority of Global Initiative for Chronic Obstructive Lung Disease (GOLD) stage I patients fail to develop clinically important COPD, even if they are persistent smokers [9]. Furthermore, GOLD stage I patients present similar characteristics, in terms of respiratory symptoms and exercise capacity, to smokers with normal spirometry. In contrast, other studies suggest that the decline in lung function is much faster in the early stages than in the advanced stages of the disease, mainly among symptomatic patients [10]. Recent studies of long-term cohorts have shown that the majority of patients do not progress to the most advanced phases of the disease, although the presence of mild obstruction predisposes to a more rapid fall of FEV1. LANGE et al. [11], showed that the combination of low baseline lung function and rapid decline, as defined by a mean annual loss of $\geqslant 40 \mathrm{~mL} \mathrm{FEV1}$, results in a greater risk of development of COPD compared to subjects having only one or none of these traits; this was independently replicated in the Lovelace cohort [12].

TABLE 1 Proposed functional definitions of early chronic obstructive pulmonary disease (COPD) and activity

\section{Mild COPD}

\section{Early COPD}

Early COPD with low disease activity

Early COPD with high disease activity

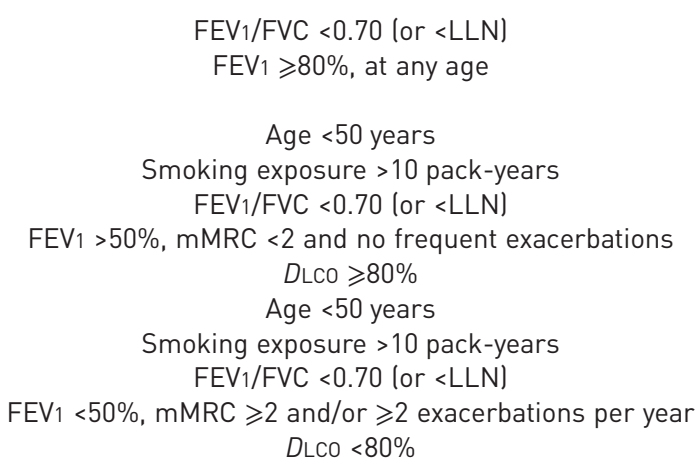

All spirometry values are post-bronchodilator; smoking exposure $>10$ pack-years refers also to an equivalent biomass exposure. FEV1: forced expiratory volume in $1 \mathrm{~s}$; FVC: forced vital capacity; LLN: lower limit of normal; mMRC: modified Medical Research Council score; DLCO: diffusing capacity of the lung for carbon monoxide. 
Articles for this review article were identified from searches of PubMed and references from relevant articles, published in English with the search terms "COPD", "emphysema", "chronic bronchitis", "early origins", "lung development", "early childhood exposures", "low birth weight", "intrauterine growth retardation", "stunting" and "foetal growth restriction".

\section{Epidemiology of early COPD}

No information is available on the impact of COPD of recent onset, so data must be extrapolated from what is known for mild COPD. In Spain, the EPISCAN (Epidemiological Study of COPD in Spain) study on the prevalence of COPD, established that mild COPD accounted for $56 \%$ of all patients diagnosed with COPD, although $73 \%$ of subjects with COPD remained undiagnosed [13]. In this study, the global prevalence of COPD in smokers or ex-smokers aged $<50$ years was $4.1 \%$ (95\% CI 2.9-5.4\%). Other studies yield similar figures [14]. The Global Burden of Disease (GBD) study, by extrapolating data from multiple studies, identifies a large geographical heterogeneity of COPD prevalence in those aged $<50$ years by country; prevalence is highest in males in Papua New Guinea (4.99\%) and United Arab Emirates (4.35\%), and in females in Papua New Guinea (6.16\%) and Taiwan (6.01\%) (figure 1) [15].

As exemplified by the Asian Network for Obstructive Lung Disease (ANOLD) [16], Burden of Obstructive Lung Disease (BOLD) [14] and GBD [15] studies, there is a large international and intranational heterogeneity in all COPD epidemiological estimators. Of interest, BOLD recently suggested that in BOLD sites, even adjusting by tobacco history, national COPD mortality rates were more strongly associated with spirometric restriction rather than obstruction, especially in those aged $<60$ years [17], therefore connecting stunting with lung development and early COPD and restriction.

This universal underdiagnosis, together with the lack of information about the risk of progression of the disease, makes it difficult to predict the true impact of the disease. However, patients with mild COPD and respiratory symptoms demand more healthcare and consume more health resources than those with the same degree of disease who are asymptomatic [18].

Initially, epidemiologists did not include mild COPD in the epidemiological definitions of the disease, for the sake of uniformity [19]. A definition of early COPD depends in part on smoking history and implies anatomical changes in the absence of airflow obstruction.

Worldwide variations in the way COPD arises probably reflect differing prevalence of smoking, with which chronic cough and phlegm are closely associated, but also a combination of other exposures that interact differently during lung development (figure 2) [20], ageing and sex distribution [21]. Collectively, these data indicate a strong association of smoking in early adulthood with lung function decline, and imply that the impact of smoke exposure in susceptible smokers is detectable with exposures as little as 8-10 pack-years, in their late thirties to early forties. Importantly, an early COPD definition does not exclude previous asthma, which has been recently reported as an important risk factor for development of fixed airflow obstruction. Within the European Community Respiratory Health Survey (ECRHS) study, early-onset asthma was observed in $26 \%$ of those diagnosed with COPD at a mean age of 37 years, which
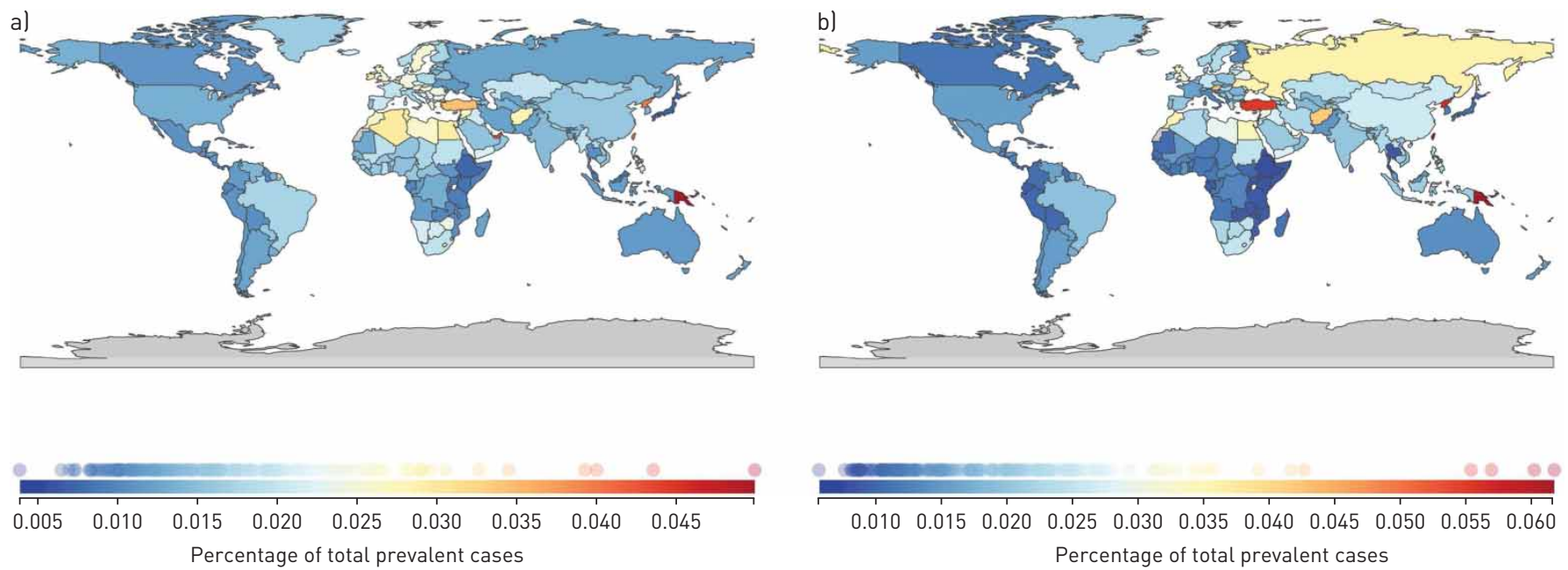

FIGURE 1 Geographical variability of chronic obstructive pulmonary disease (COPD) prevalence in those aged <50 years in a) males and b) females, according to the Global Burden of Disease study (2017). Reproduced from [15] with permission. 


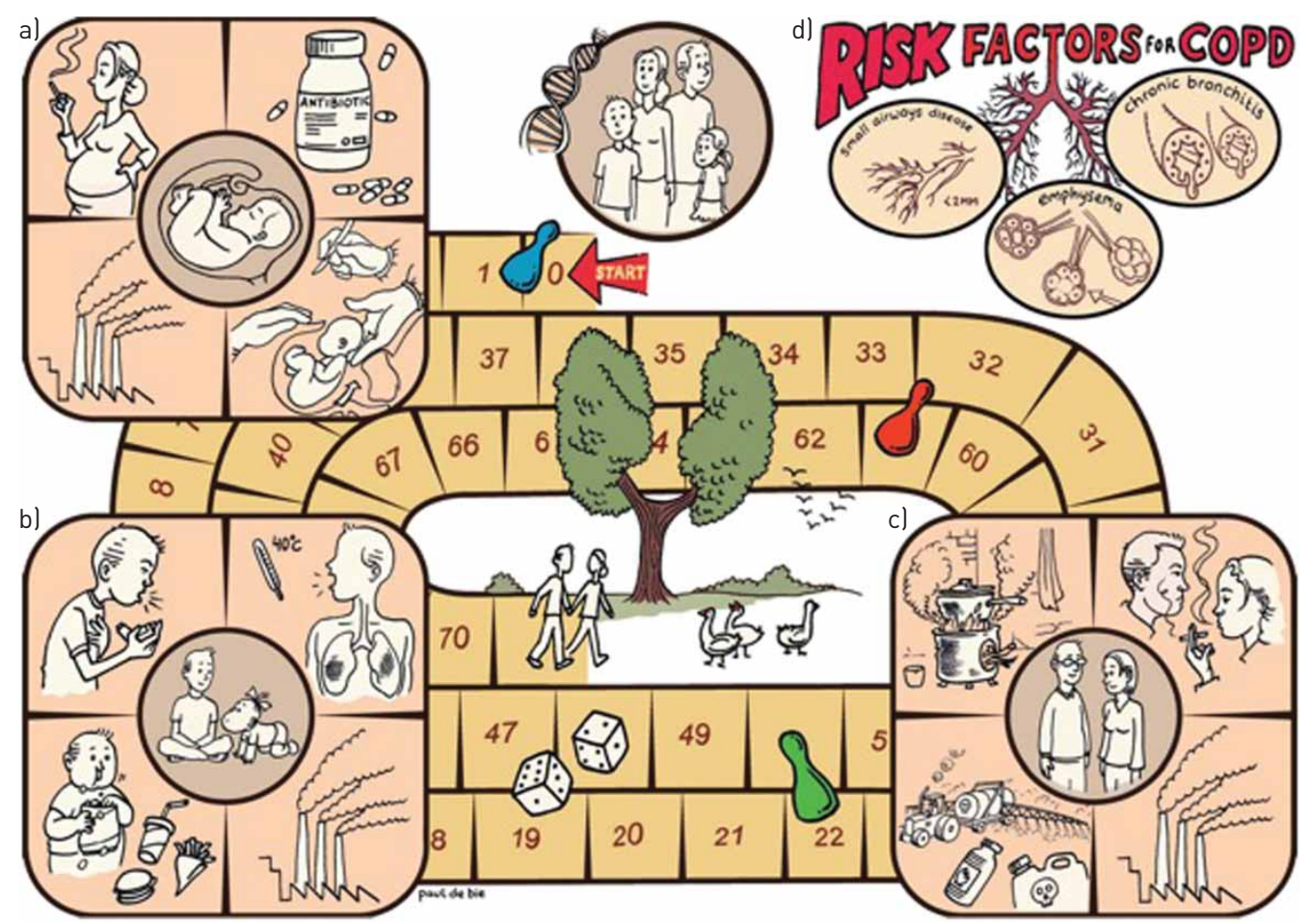

FIGURE 2 Graphic representation of the risk factors for chronic obstructive pulmonary disease (COPD) during the different stages of life. Risk factors are shown for al in utero and perinatal life; b) early childhood; and c) adulthood. d) General risk factors. Reproduced and modified from [20] with permission.

represents a 20 -fold increased risk of adult airway obstruction compared with those without asthma diagnosis [22].

Smoking during adolescence reduces peak lung function values [23]. In an approximation of the "infamous" Fletcher and Peto curves, the BODE cohort demonstrated that clinical COPD patients aged $<55$ years might have similar severity distributions (figure 3) and FEV1 decline trajectories to patients aged $>65$ years (figure 4) [24]. Although adverse early-life exposures are common, their precise contribution to adult COPD remains unclear and merits exploration, but should not be considered exclusionary in an operational definition of early COPD.

Childhood stunting, a condition that is defined as height for age below the fifth percentile on a reference growth curve, affects a large percentage of the world's youth. It measures the nutritional status of children, and it is an important indicator of the prevalence of malnutrition or other nutrition-related disorders among an identified population in a given region or area. The effect of stunting on lung development and eventually COPD is yet unknown. Merging global children needs with adult respiratory epidemiology may yield to advancing in our understanding of determinants of early COPD trends.

Other factors that have been implied in a rapid decline in lung function during early adulthood include emphysema on CT scan [25], low diffusing capacity of the lung for carbon monoxide (DLCO) [26], gas trapping on inspiratory/expiratory CT scan [27] or airway hyperresponsiveness [28]. However, a substantial part of individual variation of FEV1 decline can be explained by routinely measured clinical variables (age, weight, smoking burden, etc.) [29].

\section{Pathology and molecular implications}

Moving to histological and molecular evidence, COPD develops slowly over decades as small airways narrow and disappear, causing lung function to decline [30,31]. As inflammation develops in the lungs of (nearly) all smokers, sequential, stereotypical changes in distal airways happen only in a few susceptible smokers, leading to accelerated loss of lung function [32]. The introduction of micro-CT has shown that the destruction of the terminal bronchioles is well-established when the emphysematous lesions become large enough to be visualised on thoracic multidetector CT scans [33]. Importantly, one recent study showed that early COPD is characterised by destruction and loss of the terminal and transitional bronchioles before a decline in lung function is observed, even in the absence of emphysematous 

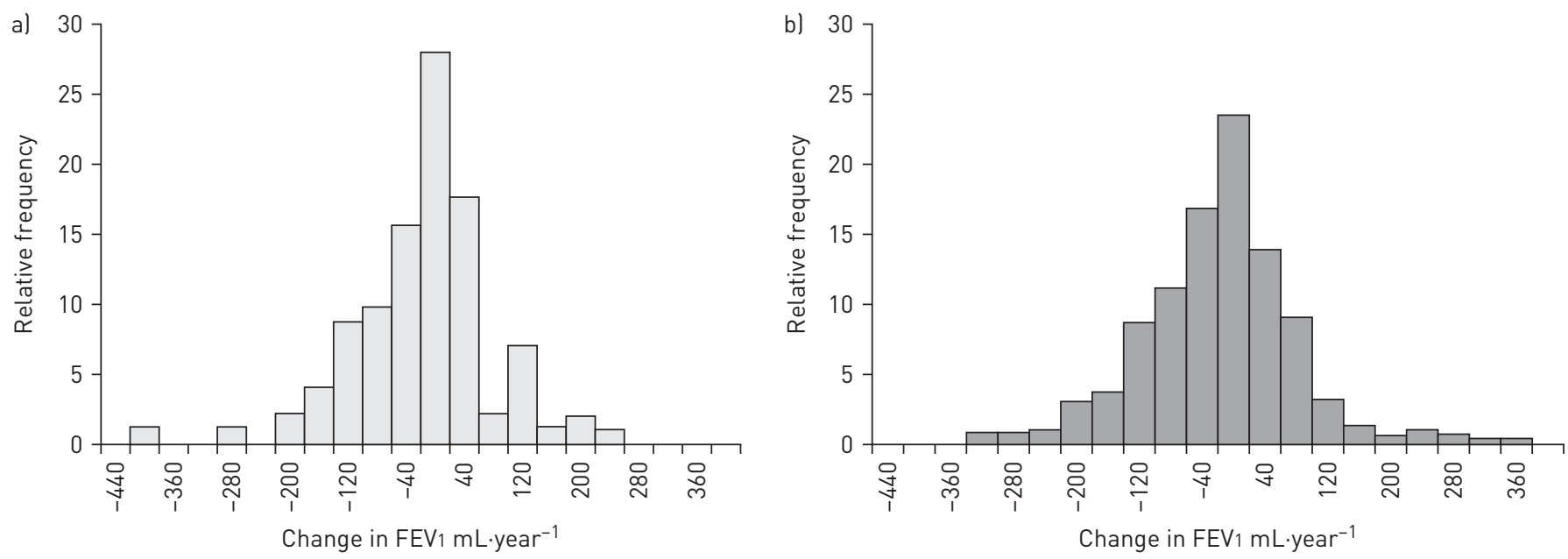

FIGURE 3 Distribution in mean annual changes in lung function in the body mass index, airflow obstruction, dyspnoea and exercise capacity (BODE) chronic obstructive pulmonary disease cohort by age group a) $<55$ years; b) $>65$ years. FEV 1 : forced expiratory volume in $1 \mathrm{~s}$. Reproduced from [24] with permission.

destruction, whereas the surviving airways have narrowed lumens and thickened walls [34]. This finding has important clinical implications, as several large clinical trials targeting severe COPD may have failed because they were initiated in patients who already had "irreversible disease" characterised by parenchymal destruction and remodelling of vast numbers of terminal and transitional bronchioles (table 2).

Another early effect of cigarette smoke is the epigenetic reprogramming, remodelling and hyperplasia of airway basal cells, the stem/progenitor cells of the ciliated and secretory cells that are central to pulmonary host defence, initially without inflammatory cell infiltration [35]. Small airway epithelium basal/progenitor cells from COPD smokers, and to a lesser extent from smokers without COPD, are limited in their ability to regenerate a fully differentiated epithelium [36-38]. In COPD, the decreased number, self-renewal and

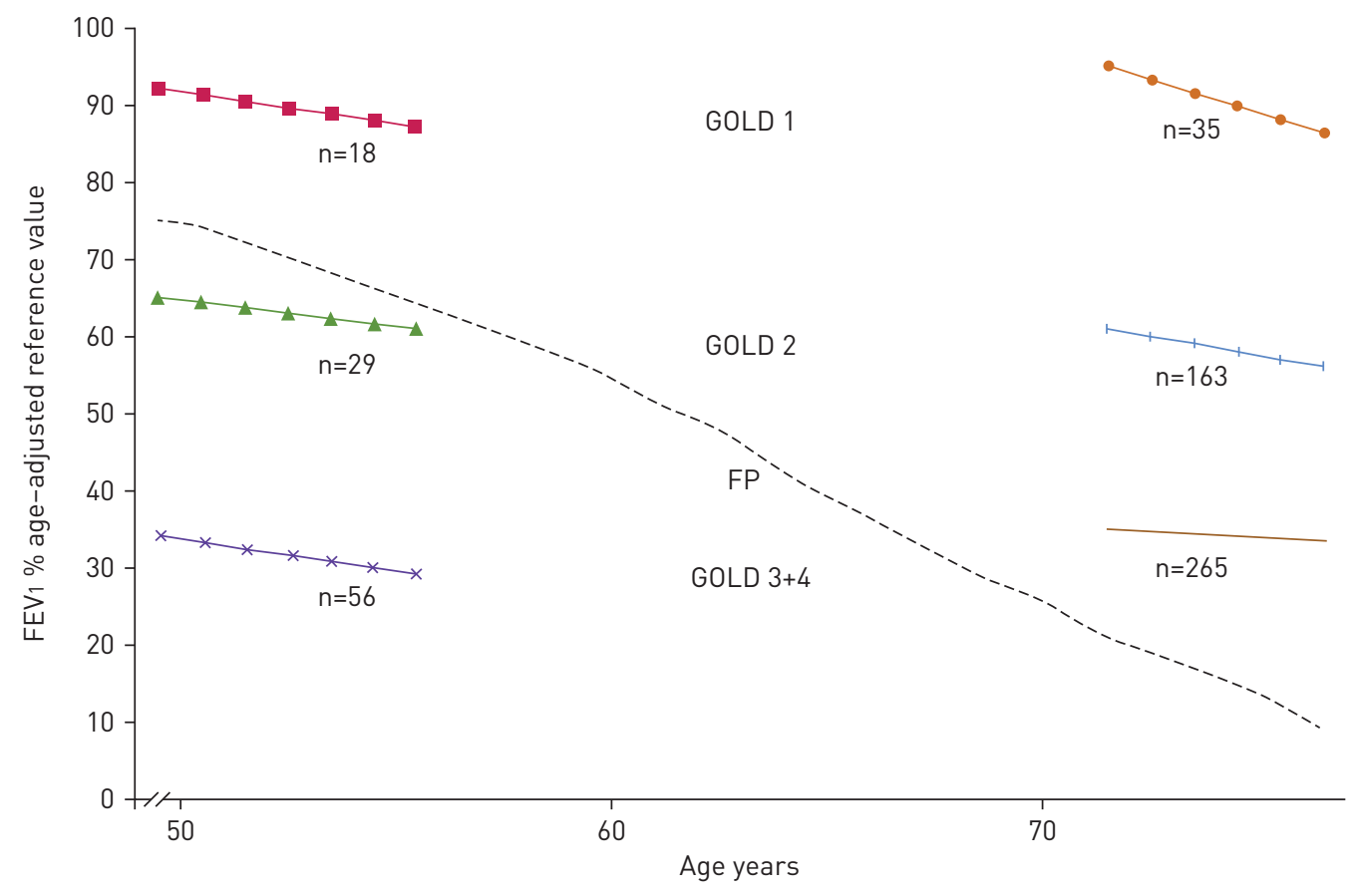

FIGURE 4 Lung function progression expressed as forced expiratory volume in $1 \mathrm{~s}$ (FEV1), stratified by Global Initiative for Chronic Obstructive Lung Disease (GOLD) grades (1,2 and 3+4) and by age group, compared with the curve from Fletcher and Peto for smokers (FP). Reproduced from [24] with permission. 
TABLE 2 Risk factors of early chronic obstructive pulmonary disease (COPD), by age

Prenatal

Maternal smoking

Family history of COPD and/or asthma/atopy

Atopy

Genetic factors

Anatomic variations of the lung: bronchopulmonary dysplasia

Malnutrition

Perinatal

Parental smoking and/or exposure to pollution

Antibiotic use

Non-vaginal birth

Preterm birth

Undernourishment/stunting

Low lung function at birth and/or ARDS at birth

Low birth weight

Childhood and early life

Second-hand smoke exposure

Active smoking during childhood/adolescence

Lower respiratory tract infections (especially respiratory syncytial virus)

Indoor/outdoor air pollution

Childhood asthma

Bronchial hyperresponsiveness

Occupational exposures

Undernourishment/stunting

Emphysema on CT scan

Gas trapping on inspiratory/expiratory CT scan

Psychosocial stress

ARDS: acute respiratory distress syndrome; CT: computed tomography.

multipotentiality of airway basal progenitor cells relates to impaired lung function, and might identify a subset of people representing an early, prediagnostic stage of COPD [39].

Little is known about the initial steps in the activation and spreading of the innate and adaptive immune systems in early COPD. It was initially postulated that the innate immune inflammation drives the mild stages of COPD, whereas in more advanced COPD, adaptive $\mathrm{T}$ - and B-cell responses become predominant. This concept has now been called into question. The involvement of innate and adaptive immune responses might not be sequential [40], but might occur at the same time early in life as a result of individual susceptibility to several factors apart from active cigarette smoking, such as air pollution, maternal smoking, asthma and infections in childhood determining the development of airflow obstruction at a young age [41]. The destructive remodelling processes observed in both bronchiolar and alveolar tissue in COPD, are associated with the infiltration of macrophages, CD4 and CD8 cells and B-cells, combined with increased formation of tertiary lymphoid organs as the disease progresses [42], indicating that innate and adaptive immune systems act simultaneously during the entire onset and progression of COPD. Additionally, dendritic cells serve as bridge between innate and adaptive immune responses and have emerged as key players in both pathological processes from the earliest to the later stages of COPD pathogenesis (table 3) [43].

A loss of peripheral tolerance to self-antigens is another important early event contributing to lung parenchymal destruction in smokers with emphysema [44]. Ever-smokers with emphysema present autoreactive T-cells in their peripheral blood long after smoking cessation, and the degree of activated T-cells correlates with loss of lung function [45]. Auto-antigens to lung components such as elastin appear during either abnormal lung development or abnormal tissue repair process. Active smokers with increased cytokine responses to self-antigens have a higher rate of emphysema progression. This could induce a host response that prevents the lung from developing normal maximal flows in and out of the lungs by the age of 25 years, thus representing a risk factor for the development of early COPD. Regulatory T-cells (Treg) are subsets of $\mathrm{CD}^{+}$T-cells with immunoregulatory functions, which inhibit autoimmunity and suppress inflammation. Smokers with COPD have a loss of Tregs in lung parenchyma and in bronchoalveolar lavage compared with smokers without COPD [46, 47]. Also, in COPD, Tregs are highly suppressive and $\mathrm{T}$ effector cells express an exhausted phenotype, with a dysregulation of immune checkpoint axes leading to excessive T-cell inflammation as a consequence of acute infection, which may be an additional cause for T-cell dysfunction. Importantly, the frequency of highly suppressive Tregs has a direct relationship with lung function of patients with COPD (table 3) [48]. 


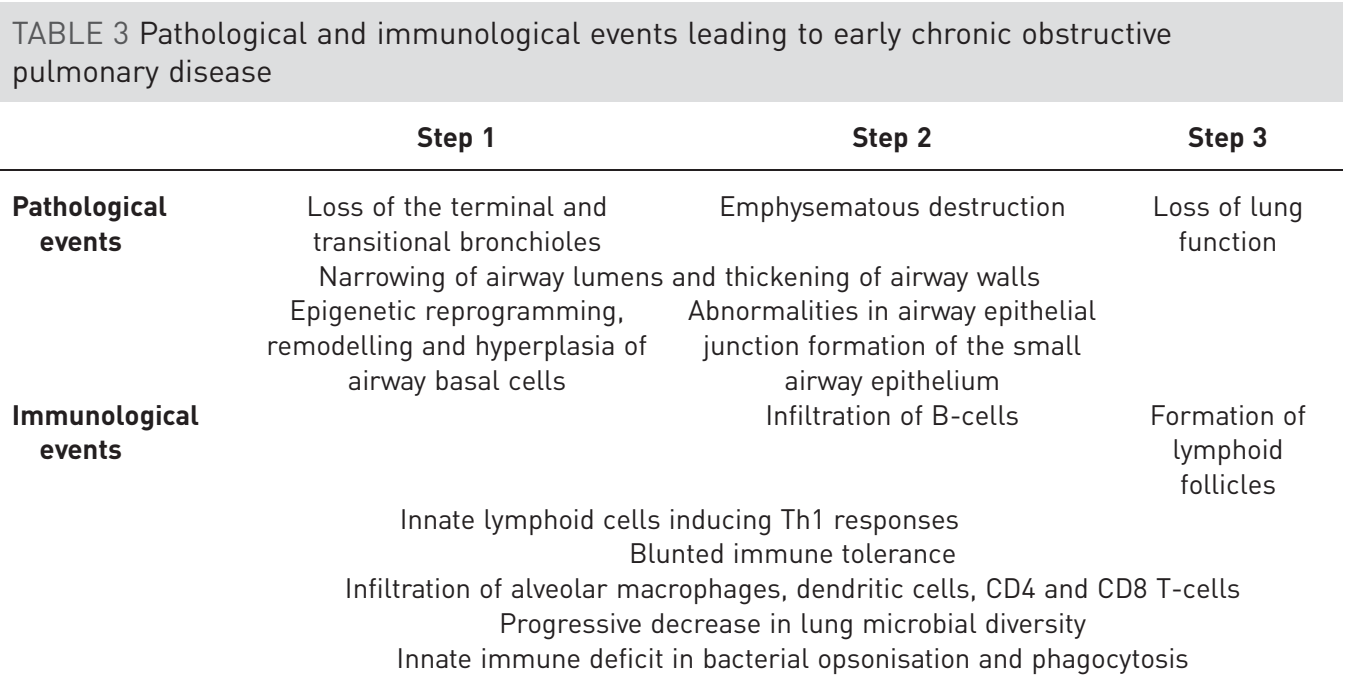

Th1: T-helper type 1 cells.

Increased numbers of B-cells, either aggregated or scattered in lymphoid follicles, are found in the parenchyma and in both small and large airways from patients with emphysema-predominant COPD [49-51]. A transcriptomics study reported an enrichment in B-cell-related genes in patients with COPD with high-resolution CT-defined emphysema that was absent in chronic bronchitis [52]. However, to date, the presence of B-cells and lymphoid follicles is regarded as a late event in the pathogenesis of COPD and there is a lack of studies linking the presence of B-cells with the early onset of COPD. Innate immune lymphoid cells (ILCs) have been detected in human lung tissue [53]. Specific subsets of ILCs deliver potent innate immune stimuli to promote Th1 responses and activate CD4, CD8 and B-cells without the requirement for antigen presentation [54]. Interestingly, the appearance of COPD is associated to the colonisation of the bronchial tree by potentially pathogenic micro-organisms from its early stages, and a decline in microbial diversity is associated with emphysematous lung destruction [55]. Thus, the susceptibility of some smokers to develop early onset COPD might be explained if ILCs stimulation induced a specific Th1 response to microbial antigens in early stages of the disease. In addition, this suggests a direct effect of the lung microbiome on the onset and progression of COPD (table 3). A blunted innate and/or adaptive immune system contributes to recurring infections in COPD. COPD alveolar macrophages have impaired phagocytosis of Streptococcus pneumoniae and a selective defect in uptake of opsonised bacteria, but these defects are mostly associated with COPD exacerbation frequency [56]. Conversely, infections in the early age (e.g. respiratory syncytial virus) increase susceptibility to cigarette smoke or biomass exposure, directly contributing to early onset of COPD. Thus, it is still unclear whether a primary deficit in the innate/adaptive immune system development and function precedes the microbial colonisation, infections and development of the inflammatory process in COPD, or vice versa (table 3).

One important unanswered question is why some smokers develop COPD at an early age, whereas others develop lung cancer. Interestingly, the incidence of lung cancer appears lower in younger patients with GOLD stage III-IV COPD compared with older patients with GOLD stage I-II COPD [57, 58] One hypothesis is that the dysfunctional activation of the immune system by noxious stimuli such as cigarette smoke becomes a double-edged sword: in some individuals, the immune system is hyperactivated, thus leading to the severe stages of COPD, emphysematous destruction and autoimmunity. In others, immune escape mechanisms prevail [59], in order to evade COPD, thus facilitating the development of cancer. Anti-inflammatory therapies attempting to modify COPD progression might also suppress key protective functions of our body system and thus should be approached carefully.

Genetic factors might contribute to the development of COPD in young individuals, but knowledge gaps in their exact role in early COPD still exist. There is a dose-dependent relationship between telomere length and pack-years of smoking [60]. In addition, cigarette smoke alters mitochondrial structure and function especially in airway epithelial cells [61-63]. However, as the development of the persistent airflow limitation characteristic of COPD is not always a result of accelerated decline in FEV1, but can be due to an abnormal lung development in childhood, ageing may not always be a pathogenic mechanism in those individuals who develop COPD early in life [64]. 


\section{Clinical implications}

Diagnosis of COPD of recent onset

Spirometry is considered the fundamental tool for the diagnosis of COPD according to GOLD [4]. However, despite being "normal" according to GOLD, smokers with normal spirometry but low DLCO are at significant risk of developing COPD with obstruction to airflow [24].

To date, no other markers of the disease are known to predict which patients with COPD of recent onset will progress to a greater severity/worse prognosis of the disease. The ECLIPSE (Evaluation of COPD Longitudinally to Identify Predictive Surrogate End-points) study identified a subgroup of patients with an accelerated loss of lung function [65], which can be considered as an indirect marker of activity. Similarly, an increase in symptoms or frequent exacerbations $[18,66]$ could be considered as indirect markers of activity.

Therefore, the search for signs of disease activity is especially relevant in patients with COPD of recent onset. For this reason, we propose a strategic view of the concept of COPD of recent onset (table 1).

\section{Prevention and treatment of COPD of recent onset}

Of the many causes of COPD, cigarette smoking is by far the most important. Smoking cessation is the main intervention in order to prevent the development of COPD. If achieved early enough, smoking cessation reduces the incidence of respiratory morbidity and incident COPD [67]. There are several studies showing that intervention in phases of lesser COPD severity can have an impact on the evolution of the disease (table 4), although none of these phases would fit the definition of early COPD. The Lung Health Study showed that an intensive smoking cessation programme was associated with improvements in lung function at 5 years in patients with mild and moderate COPD (FEV1 >50\%) [68]. A recent clinical trial in patients with COPD GOLD stages I and II using tiotropium versus placebo demonstrated a modest improvement in FEV1 decline [69]. Other clinical trials with post hoc analysis focused on GOLD stage II patients such as UPLIFT (Understanding Potential Long-term Impacts on Function with Tiotropium) [70], or TORCH (Towards a Revolution in COPD Health) [71] have also demonstrated a significant effect of the pharmacological intervention on lung function and exacerbations. Moreover, the secondary analyses of COPD patients aged $<50$ years in UPLIFT suggested an effect of the pharmacological intervention on lung function and symptoms [72].

The concept of COPD as an inflammatory disease has led to the exploration of anti-inflammatory drug therapies. However, all of them failed to modify the natural course of the disease. The European Respiratory Study on Chronic Obstructive Pulmonary Disease (EUROSCOP) [73], failed to demonstrate a benefit of budesonide in individuals with post-bronchodilator $\mathrm{FEV}_{1}>50 \%$ predicted and $\mathrm{FEV} 1 / \mathrm{FVC}<70 \%$ who continued smoking. Similarly, the Copenhagen City Heart Study [74], the Lung Health Study II [75] and the ISOLDE (Inhaled Steroids in Obstructive Lung Disease in Europe) trial [76] did not show a beneficial effect of inhaled corticosteroids on the rate of decline in FEV1 in patients with mild-moderate disease.

TABLE 4 Trials exploring mild stages of chronic obstructive pulmonary disease

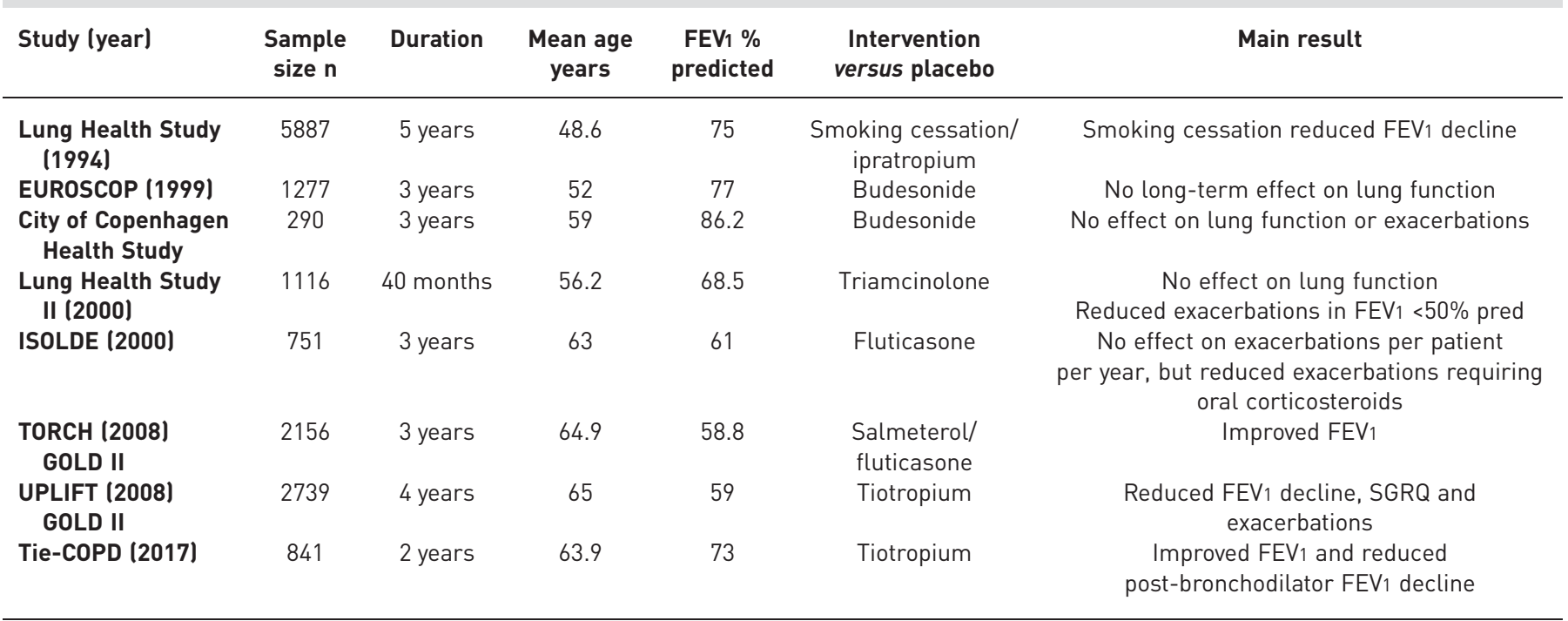

FEV1: forced expiratory volume in $1 \mathrm{~s}$; SGRQ: St George's Respiratory Questionnaire. 


\section{Future investigations}

Determinants of disease progression are still unknown and efforts should be made in order to understand the main factors that contribute to disease activity from early stages. The role of asthma and COPD overlap [77, 78], and the potential ethnic differences in COPD expression and progression [79] are unchartered territories that will require new research efforts on early COPD.

Several trials are ongoing in order to study cohorts of young patients with COPD such as the British Lung Foundation Early COPD Development study in the UK (ClinicalTrials.gov identifier NCT03480347) or the study of Determinants of Onset and Progression of COPD in Young Adults (EARLY COPD) in Spain (ClinicalTrials.gov identifier NCT02352220). From a therapeutic point of view, the effects of treatment in the early stages of COPD or even in symptomatic patients without airflow limitation are still unknown. A clinical trial using indacaterol/glycopyrronium versus placebo in symptomatic smokers with $\mathrm{FEV} 1 / \mathrm{FVC}$ $>0.70$ is currently recruiting patients (RETHINC: Redefining Therapy in Early COPD for the Pulmonary Trials Cooperative; ClinicalTrials.gov identifier NCT02867761). Finally, the interaction between early COPD and the development of comorbidities needs to be investigated from the clinical and biological points of view.

In contrast to the topic of this review, just as we have late-onset asthma, we may have late-onset COPD in individuals aged $\geqslant 80$ years, an age near the median life span in both sexes in many countries [80]; hence, how this phenomenon contrasts with early-onset stable and early-onset progressive COPD are concepts that might be further explored.

\section{Conclusions}

COPD has always been considered a disease of the elderly, and little attention has been paid to the clinical and pathologic features of COPD in younger individuals. Current evidence suggests that early COPD is associated with poor clinical outcomes and it makes sense to think that early detection, diagnosis and maintenance treatment of COPD, alongside smoking cessation and exercise, may help to provide the best symptom control, disease progression and outcomes in COPD.

Conflict of interest: J.B. Soriano declares having received pharmaceutical company grants from GSK in 2011 and Chiesi in 2012 via CIMERA, his former home institution, and from 2014 to date from Linde via Hospital Universitario de La Princesa; and participated in speaking activities, advisory committees and consultancies during the period 2011-2017 sponsored by: Almirall, AstraZeneca, Boehringer Ingelheim, CHEST, Chiesi, ERS, GEBRO, Grifols, GSK, Linde, Lipopharma, Mundipharma, Novartis, Pfizer, RiRL, Rovi, Sandoz, SEPAR and Takeda. F. Polverino has nothing to disclose. B.G. Cosio reports personal fees from AstraZeneca, grants and personal fees from Boehringer-Ingelheim, grants and personal fees from Novartis, grants and personal fees from Chiesi, personal fees from Rovi, grants from Menarini and personal fees from Esteve, outside the submitted work.

\section{References}

1 Martinez FJ, Han MK, Allinson JP, et al. At the root: defining and halting progression of early chronic obstructive pulmonary disease. Am J Respir Crit Care Med 2018; 197: 1540-1551.

2 Allinson JP, Hardy R, Donaldson GC, et al. Combined impact of smoking and early life exposures on adult lung function trajectories. Am J Respir Crit Care Med 2017; 196: 1021-1030.

3 Rennard SI, Drummond MB. Early chronic obstructive pulmonary disease: definition, assessment, and prevention. Lancet 2015; 385: 1778-1788.

4 Vogelmeier CF, Criner GJ, Martinez FJ, et al. Global Strategy for the Diagnosis, Management, and Prevention of Chronic Obstructive Lung Disease 2017 Report: GOLD Executive Summary. Eur Respir J 2017; 49: 1700214.

5 Celli BR, Cote CG, Marin JM, et al. The body-mass index, airflow obstruction, dyspnea, and exercise capacity index in chronic obstructive pulmonary disease. N Engl J Med 2004; 350: 1005-1012.

6 Puhan MA, Garcia-Aymerich J, Frey M, et al. Expansion of the prognostic assessment of patients with chronic obstructive pulmonary disease: the updated BODE index and the ADO index. Lancet 2009; 374: 704-711.

7 Marin JM, Alfageme I, Almagro P, et al. Multicomponent indices to predict survival in COPD: the COCOMICS study. Eur Respir J 2013; 42: 323-332.

8 Agustí A, Celli B. Avoiding confusion in COPD: from risk factors to phenotypes to measures of disease characterisation. Eur Respir J 2011; 38: 749-751.

9 Vestbo J, Lange P. Can GOLD stage 0 provide information of prognostic value in chronic obstructive pulmonary disease? Am J Respir Crit Care Med 2002; 166: 329-332.

10 Kohansal R, Martinez-Camblor P, Agustí A, et al. The natural history of chronic airflow obstruction revisited: an analysis of the Framingham offspring cohort. Am J Respir Crit Care Med 2009; 180: 3-10.

11 Lange P, Celli B, Agustí A, et al. Lung-function trajectories leading to chronic obstructive pulmonary disease. N Engl J Med 2015; 373: 111-122.

12 Petersen $\mathrm{H}$, Sood A, Polverino F, et al. The course of lung function in middle-aged heavy smokers: incidence and time to early onset of COPD. Am J Respir Crit Care Med 2018; in press [https://doi.org/10.1164/rccm.201805-0861LE].

13 Miravitlles M, Soriano JB, García-Río F, et al. Prevalence of COPD in Spain: impact of undiagnosed COPD on quality of life and daily life activities. Thorax 2009; 64: 863-868.

14 Lamprecht B, Soriano JB, Studnicka $\mathrm{M}$, et al. Determinants of underdiagnosis of COPD in national and international surveys. Chest 2015; 148: 971-985. 
15 Institute for Health Metrics and Evaluation (IHME). GBD Compare Data Visualization. IHME, University of Washington, 2017 https://vizhub.healthdata.org/gbd-compare/ Date last accessed: November 1, 2018.

16 Loh LC, Oh YM, Lee SD, et al. The Asian Network for Obstructive Lung Disease (ANOLD)-COPD from an Asian perspective. QJM 2015; 108: 921-922.

17 Burney P, Jithoo A, Kato B, et al. Chronic obstructive pulmonary disease mortality and prevalence: the associations with smoking and poverty - a BOLD analysis. Thorax 2014; 69: 465-473.

18 Kim K, Aaron SD. What is a COPD exacerbation? Current definitions, pitfalls, challenges and opportunities for improvement. Eur Respir J 2018; 1801261.

19 Buist AS, McBurnie MA, Vollmer WM, et al. International variation in the prevalence of COPD (the BOLD Study): a population-based prevalence study. Lancet 2007; 370: 741-750.

20 Postma DS, Bush A, van den Berge M. Risk factors and early origins of chronic obstructive pulmonary disease. Lancet 2015; 385: 899-909.

21 GBD 2015 Chronic Respiratory Disease Collaborators. Global, regional, and national deaths, prevalence, disabilityadjusted life years, and years lived with disability for chronic obstructive pulmonary disease and asthma, 19902015: a systematic analysis for the Global Burden of Disease Study 2015. Lancet Respir Med 2017; 5: 691-706.

22 Aanerud M, Carsin AE, Sunyer J, et al. Interaction between asthma and smoking increases the risk of adult airway obstruction. Eur Respir J 2015; 45: 635-643.

23 Gold DR, Wang X, Wypij D, et al. Effects of cigarette smoking on lung function in adolescent boys and girls. N Engl J Med 1996; 335: 931-937.

24 Sanchez-Salcedo P, Divo M, Casanova C, et al. Disease progression in young patients with COPD: rethinking the Fletcher and Peto model. Eur Respir J 2014; 44: 324-331.

25 Galbán CJ, Han MK, Boes JL, et al. Computed tomography-based biomarker provides unique signature for diagnosis of COPD phenotypes and disease progression. Nat Med 2012; 18: 1711-1715.

26 Harvey BG, Strulovici-Barel Y, Kaner RJ, et al. Risk of COPD with obstruction in active smokers with normal spirometry and reduced diffusion capacity. Eur Respir J 2015; 46: 1589-1597.

27 Kirby M, Yin Y, Tschirren J, et al. A novel method of estimating small airway disease using inspiratory-to-expiratory computed tomography. Respiration 2017; 94: 336-345.

28 de Marco R, Accordini S, Marcon A, et al. Risk factors for chronic obstructive pulmonary disease in a European cohort of young adults. Am J Respir Crit Care Med 2011; 183: 891-897.

29 Zafari Z, Sin DD, Postma DS, et al. Individualized prediction of lung-function decline in chronic obstructive pulmonary disease. CMAJ 2016; 188: 1004-1011.

30 Hogg JC, Chu F, Utokaparch S, et al. The nature of small-airway obstruction in chronic obstructive pulmonary disease. N Engl J Med 2004; 350: 2645-2653.

31 Pons J, Sauleda J, Ferrer JM, et al. Blunted $\gamma \delta$ T-lymphocyte response in chronic obstructive pulmonary disease. Eur Respir J 2005; 25: 441-446.

32 Cosio MG, Saetta M, Agusti A. Immunologic aspects of chronic obstructive pulmonary disease. N Engl J Med 2009; 360: 2445-2454.

33 McDonough JE, Yuan R, Suzuki M, et al. Small-airway obstruction and emphysema in chronic obstructive pulmonary disease. N Engl J Med 2011; 365: 1567-1575.

34 Koo HK, Vasilescu DM, Booth S, et al. Small airways disease in mild and moderate chronic obstructive pulmonary disease: a cross-sectional study. Lancet Respir Med 2018; 6: 591-602.

35 Crystal RG. Airway basal cells. The "smoking gun" of chronic obstructive pulmonary disease. Am J Respir Crit Care Med 2014; 190: 1355-1362.

36 Staudt MR, Buro-Auriemma LJ, Walters MS, et al. Airway basal stem/progenitor cells have diminished capacity to regenerate airway epithelium in chronic obstructive pulmonary disease. Am J Respir Crit Care Med 2014; 190: 955-958.

37 Heijink IH, Noordhoek JA, Timens W, et al. Abnormalities in airway epithelial junction formation in chronic obstructive pulmonary disease. Am J Respir Crit Care Med 2014; 189: 1439-1442.

38 Shaykhiev R, Crystal RG. Early events in the pathogenesis of chronic obstructive pulmonary disease. Smoking-induced reprogramming of airway epithelial basal progenitor cells. Ann Am Thorac Soc 2014; 11: Suppl. 5, S252-S258.

39 Bernstein KE, Ong FS, Blackwell WL, et al. A modern understanding of the traditional and nontraditional biological functions of angiotensin-converting enzyme. Pharmacol Rev 2012; 65: 1-46.

40 Bhavani S, Yuan X, You R, et al. Loss of peripheral tolerance in emphysema. Phenotypes, exacerbations, and disease progression. Ann Am Thorac Soc 2015; 12: Suppl. 2, S164-S168.

41 Martinez FD. Early-life origins of chronic obstructive pulmonary disease. N Engl J Med 2016; 375: 871-878.

42 Suzuki M, Sze MA, Campbell JD, et al. The cellular and molecular determinants of emphysematous destruction in COPD. Sci Rep 2017; 7: 9562.

43 Freeman CM, Curtis JL. Lung dendritic cells: shaping immune responses throughout chronic obstructive pulmonary disease progression. Am J Respir Cell Mol Biol 2017; 56: 152-159.

44 Kheradmand F, Shan M, Xu C, et al. Autoimmunity in chronic obstructive pulmonary disease: clinical and experimental evidence. Expert Rev Clin Immunol 2012; 8: 285-292.

45 Xu C, Hesselbacher S, Tsai CL, et al. Autoreactive T cells in human smokers is predictive of clinical outcome. Front Immunol 2012; 3: 267.

46 Lee SH, Goswami S, Grudo A, et al. Antielastin autoimmunity in tobacco smoking-induced emphysema. Nat Med 2007; 13: 567-569.

47 Barceló B, Pons J, Ferrer JM, et al. Phenotypic characterisation of T-lymphocytes in COPD: abnormal CD4 ${ }^{+} \mathrm{CD} 25^{+}$ regulatory T-lymphocyte response to tobacco smoking. Eur Respir J 2008; 31: 555-562.

48 Kalathil SG, Lugade AA, Pradhan V, et al. T-regulatory cells and programmed death $1^{+} \mathrm{T}$ cells contribute to effector T-cell dysfunction in patients with chronic obstructive pulmonary disease. Am J Respir Crit Care Med 2014; 190: 40-50.

49 Polverino F, Baraldo S, Bazzan E, et al. A novel insight into adaptive immunity in chronic obstructive pulmonary disease: B cell activating factor belonging to the tumor necrosis factor family. Am J Respir Crit Care Med 2010 182: 1011-1019. 
50 Polverino F, Cosio BG, Pons J, et al. B cell-activating factor. An orchestrator of lymphoid follicles in severe chronic obstructive pulmonary disease. Am J Respir Crit Care Med 2015; 192: 695-705.

51 Polverino F, Seys LJ, Bracke KR, et al. B cells in chronic obstructive pulmonary disease: moving to center stage. Am J Physiol Lung Cell Mol Physiol 2016; 311: L687-L695.

52 Faner R, Cruz T, Casserras T, et al. Network analysis of lung transcriptomics reveals a distinct B-cell signature in emphysema. Am J Respir Crit Care Med 2016; 193: 1242-1253.

53 De Grove KC, Provoost S, Verhamme FM, et al. Characterization and quantification of innate lymphoid cell subsets in human lung. PLoS One 2016; 11: e0145961.

54 Kim M, Kim CH. Colonization and effector functions of innate lymphoid cells in mucosal tissues. Microbes Infect 2016; 18: 604-614.

55 Sze MA, Dimitriu PA, Suzuki M, et al. Host response to the lung microbiome in chronic obstructive pulmonary disease. Am J Respir Crit Care Med 2015; 192: 438-445.

56 Bewley MA, Budd RC, Ryan E, et al. Opsonic phagocytosis in chronic obstructive pulmonary disease is enhanced by Nrf2 agonists. Am J Respir Crit Care Med 2018; 198: 739-750.

57 de Torres JP, Marín JM, Casanova C, et al. Lung cancer in patients with chronic obstructive pulmonary disease incidence and predicting factors. Am J Respir Crit Care Med 2011; 184: 913-919.

58 Mark NM, Kargl J, Busch SE, et al. Chronic obstructive pulmonary disease alters immune cell composition and immune checkpoint inhibitor efficacy in non-small cell lung cancer. Am J Respir Crit Care Med 2018; 197: $325-336$.

59 Biton J, Ouakrim H, Dechartres A, et al. Impaired tumor-infiltrating T cells in patients with COPD impact lung cancer response to PD-1 blockade. Am J Respir Crit Care Med 2018; 198: 928-940.

60 Morlá M, Busquets X, Pons J, et al. Telomere shortening in smokers with and without COPD. Eur Respir J 2006; 27: 525-528.

61 Ballweg K, Mutze K, Königshoff M, et al. Cigarette smoke extract affects mitochondrial function in alveolar epithelial cells. Am J Physiol Lung Cell Mol Physiol 2014; 307: L895-L907.

62 Hara H, Araya J, Ito S, et al. Mitochondrial fragmentation in cigarette smoke-induced bronchial epithelial cell senescence. Am J Physiol Lung Cell Mol Physiol 2013; 305: L737-L746.

63 Mizumura K, Cloonan SM, Nakahira K, et al. Mitophagy-dependent necroptosis contributes to the pathogenesis of COPD. J Clin Invest 2014; 124: 3987-4003.

64 MacNee W. Is chronic obstructive pulmonary disease an accelerated aging disease? Ann Am Thorac Soc 2016; 13: Suppl. 5, S429-S437.

65 Vestbo J, Edwards LD, Scanlon PD, et al. Changes in forced expiratory volume in 1 second over time in COPD. N Engl J Med 2011; 365: 1184-1192.

66 Hurst JR, Vestbo J, Anzueto A, et al. Susceptibility to exacerbation in chronic obstructive pulmonary disease. N Engl J Med 2010; 363: 1128-1138.

67 US Public Health Service, Office of the Surgeon General and Office on Smoking and Health. The Health Benefits of Smoking Cessation. A Report of the Surgeon General. Washington, DC, US Public Health Service, Office on Smoking and Health, 1990.

68 Anthonisen NR, Connett JE, Kiley JP, et al. Effects of smoking intervention and the use of an inhaled anticholinergic bronchodilator on the rate of decline of FEV1. The Lung Health Study. JAMA 1994; 272: 1497-1505.

69 Zhou Y, Zhong NS, Li X, et al. Tiotropium in early-stage chronic obstructive pulmonary disease. $N$ Engl J Med 2017; 377: 923-935.

70 Decramer M, Celli B, Kesten S, et al. Effect of tiotropium on outcomes in patients with moderate chronic obstructive pulmonary disease (UPLIFT): a prespecified subgroup analysis of a randomised controlled trial. Lancet 2009; 374: 1171-1178.

71 Jenkins CR, Jones PW, Calverley PM, et al. Efficacy of salmeterol/fluticasone propionate by GOLD stage of chronic obstructive pulmonary disease: analysis from the randomised, placebo-controlled TORCH study. Respir Res 2009; 10: 59 .

72 Morice AH, Celli B, Kesten S, et al. COPD in young patients: a pre-specified analysis of the four-year trial of tiotropium (UPLIFT). Respir Med 2010; 104: 1659-1667.

73 Pauwels RA, Löfdahl CG, Laitinen LA, et al. Long-term treatment with inhaled budesonide in persons with mild chronic obstructive pulmonary disease who continue smoking. European Respiratory Society Study on Chronic Obstructive Pulmonary Disease. N Engl J Med 1999; 340: 1948-1953.

74 Vestbo J, Sørensen T, Lange P, et al. Long-term effect of inhaled budesonide in mild and moderate chronic obstructive pulmonary disease: a randomised controlled trial. Lancet 1999; 353: 1819-1823.

75 The Lung Health Study Research Group. Effect of inhaled triamcinolone on the decline in pulmonary function in chronic obstructive pulmonary disease. N Engl J Med 2000; 343: 1902-1909.

76 Burge PS, Calverley PM, Jones PW, et al. Randomised, double blind, placebo controlled study of fluticasone propionate in patients with moderate to severe chronic obstructive pulmonary disease: the ISOLDE trial. BMJ 2000; 320: 1297-1303.

77 Poh TY, Mac Aogáin M, Chan AK, et al. Understanding COPD-overlap syndromes. Expert Rev Respir Med 2017; 11: 285-298.

78 Sin DD, Miravitlles M, Mannino DM, et al. What is asthma-COPD overlap syndrome? Towards a consensus definition from a round table discussion. Eur Respir J 2016; 48: 664-673.

79 Nishimura M. Similarities and differences between East and West in COPD. Respirology 2016; $21: 1340-1341$.

80 GBD 2016 DALYs and HALE Collaborators. Global, regional, and national disability-adjusted life-years (DALYs) for 333 diseases and injuries and healthy life expectancy (HALE) for 195 countries and territories, 1990-2016: a systematic analysis for the Global Burden of Disease Study 2016. Lancet 2017; 390: 1260-1344. 